\title{
Kinetics of Hydrogen Evolution on Copper Electrode Involving Organic Acids as Proton Donors
}

\author{
A. Survila, S. Kanapeckaitè, J. Pileckiené, and J. Būdienè \\ Center for Physical Sciences and Technology, Institute of Chemistry, A. Goštauto 9, 01108 Vilnius, Lithuania \\ Correspondence should be addressed to A. Survila, arvydass@ktl.mii.lt \\ Received 10 March 2011; Accepted 17 May 2011 \\ Academic Editor: Bengi Uslu
}

Copyright ( 2011 A. Survila et al. This is an open access article distributed under the Creative Commons Attribution License, which permits unrestricted use, distribution, and reproduction in any medium, provided the original work is properly cited.

Linear potential sweep (LPS) voltammetry was applied to study the kinetics of hydrogen evolution in solutions containing glycolic, malic, tartaric, and gluconic acids. The CE mechanism of hydrogen evolution was analyzed invoking the 2nd Fick's law equations supplemented by terms that account for chemical interactions between diffusing particles. Acids are considered as components that are capable of releasing hydrated protons taking part in the charge-transfer step. Current peaks observed on LPS voltammograms are in linear dependence on $\sqrt{\nu}$ ( $\nu$ is the potential sweep rate). They obey well-known relationships obtained for simple redox processes, provided that the concentration of oxidant is treated as total concentration of proton donors. Determination of surface concentrations as current density functions makes it possible to transform LPS voltammograms into linear Tafel plots normalized with respect to the surface concentration of hydronium ions. Similar kinetic parameters $\left(\alpha \approx 0.6\right.$ and $\left.i_{0} \approx 10 \mu \mathrm{A} \mathrm{cm}{ }^{-2}\right) \mathrm{obtained}$ at $\mathrm{pH} 3$ for all $\mathrm{OA}$ solutions indicate that the nature of OA has no noticeable influence on the charge-transfer process.

\section{Introduction}

Organic acids containing $\mathrm{OH}$ groups are often used as ligands capable of forming quite stable coordination compounds with different metals including copper. Due to their environmental compatibility, most of them have found use in various industrial applications. Tartaric and citric acids are used in plating baths as additives producing compact, fine-grained copper coatings. Besides, electroless plating of dielectrics involving $\mathrm{Cu}(\mathrm{II})$-tartrate complexes is also worthy of mention.

Hydrogen evolution often attends the electrodeposition of metals. This side reaction should be taken into account when the main process is studied. Often the reduction of hydronium ions can be complicated and involves some chemical steps. In the case of CE mechanism (chemical + electrochemical step), electroactive particles are formed in a chemical reaction that precedes the electron transfer step. Components that produce hydronium ions are often referred to as proton donors. Aforementioned organic acids, which are commonly added to improve the coatings, can also play such a role.
Fundamentals of CE processes, that have been substantially elaborated for present (see, e.g., [1-3]), can serve as a basis for studies of hydrogen evolution. However, some difficulties emerge, when a wide range of proton donors is considered; then, certain extensions and generalizations are desirable. The literature data on this problem show that the knowledge in this area is not sound. Therefore, the investigations of kinetics and mechanism of hydrogen evolution in such systems still remain an actual problem. In this connection, we referred to some concepts [4] that have been applied by us for reduction of metal complexes. This paper presents the main characteristics of the processes occurring on the copper electrode in solutions containing some organic acids that act as proton donors.

\section{Experimental Details}

Solutions under investigation contained $0.04 \mathrm{M}$ analytical grade glycolic, malic, or tartaric acid (Reakhim, Russia), 0.02 or $0.05 \mathrm{M}$ sodium gluconate (Sigma-Aldrich, 99\% purity). $0.3 \mathrm{M} \mathrm{Na}_{2} \mathrm{SO}_{4}$ or $\mathrm{K}_{2} \mathrm{SO}_{4}$ (Reakhim, Russia, high purity) and $0.5 \mathrm{M} \mathrm{Na}_{2} \mathrm{SO}_{4}$ (Lach-Ner, Czech Republic, 99\% purity) 
served as supporting electrolytes. Some experiments were carried out with addition of $0.01 \mathrm{M} \mathrm{CuSO}_{4}$ ( Mallinckrodt, USA). Specified values of $\mathrm{pH}$ were adjusted by addition of $\mathrm{H}_{2} \mathrm{SO}_{4}$ or $\mathrm{KOH}$. Twice-distilled water was used to prepare solutions. A pure argon stream was passed through solutions for $0.5 \mathrm{~h}$ prior to measurements. All experiments were carried out at $20^{\circ} \mathrm{C}$.

To prepare a working electrode, a platinum disc was coated with a 5-7 $\mu \mathrm{m}$ thick copper layer in the solution containing $\left(\mathrm{g} \mathrm{dm}^{-3}\right)$ : $\mathrm{CuSO}_{4} \cdot 5 \mathrm{H}_{2} \mathrm{O}-200, \mathrm{H}_{2} \mathrm{SO}_{4}-50$ at $10 \mathrm{~mA} \mathrm{~cm}^{-2}$. Electrode potentials were measured with respect to the $\mathrm{Ag}|\mathrm{AgCl}| \mathrm{KCl}$ (sat) reference electrode and were converted to the standard hydrogen scale.

Voltammograms were recorded under linear potential sweep (LPS) conditions using a potentiostat PI-50-1 (Belorussia). Potential sweep rates $v$ ranged from 10 to $200 \mathrm{mV} \mathrm{s}^{-1}$. Some supporting experiments were carried out using a conventional RDE technique.

\section{A Quantitative Model}

Let us assume that an aqueous solution of weak acid $\mathrm{LH}_{2}$ is prepared and an excess of indifferent (supporting) electrolyte is added. The main reversible processes occurring in such a system can be depicted as follows:

$$
\begin{aligned}
\mathrm{LH}_{2} & \rightleftarrows \mathrm{LH}^{-}+\mathrm{H}^{+}, \\
\mathrm{LH}^{-} & \rightleftarrows \mathrm{L}^{2-}+\mathrm{H}^{+}, \\
\mathrm{H}_{2} \mathrm{O} & \rightleftarrows \mathrm{H}^{+}+\mathrm{OH}^{-} .
\end{aligned}
$$

Let us suppose that these equilibria are initially established.

When the reduction of hydronium ions, abbreviated as $\mathrm{H}^{+}$, starts, their surface-concentration decreases. This results in the onset of mass transport of reacting substances. To describe the latter process quantitatively, we invoke the second Fick's law supplemented by terms that account for chemical interactions between diffusing particles. Then, a set of differential equations should be written for each component, except the water that is present in a large excess. In the case of linear diffusion, these relationships take the following form:

$$
\begin{aligned}
\frac{\partial\left[\mathrm{LH}_{2}\right]}{\partial t}= & D \frac{\partial^{2}\left[\mathrm{LH}_{2}\right]}{\partial x^{2}}-k_{2}\left[\mathrm{LH}_{2}\right]+k_{-2}\left[\mathrm{LH}^{-}\right]\left[\mathrm{H}^{+}\right] \\
\frac{\partial\left[\mathrm{LH}^{-}\right]}{\partial t}= & D \frac{\partial^{2}\left[\mathrm{LH}^{-}\right]}{\partial x^{2}}+k_{2}\left[\mathrm{LH}_{2}\right]-k_{-2}\left[\mathrm{LH}^{-}\right]\left[\mathrm{H}^{+}\right] \\
& -k_{1}[\mathrm{LH}]+k_{-1}\left[\mathrm{~L}^{-}\right]\left[\mathrm{H}^{+}\right], \\
\frac{\partial\left[\mathrm{L}^{2-}\right]}{\partial t}= & D \frac{\partial^{2}\left[\mathrm{~L}^{2-}\right]}{\partial x^{2}}+k_{1}\left[\mathrm{LH}^{-}\right]-k_{-1}\left[\mathrm{~L}^{2-}\right]\left[\mathrm{H}^{+}\right], \\
\frac{\partial\left[\mathrm{H}^{+}\right]}{\partial t}= & D \frac{\partial^{2}\left[\mathrm{H}^{+}\right]}{\partial x^{2}}+k_{2}\left[\mathrm{LH}_{2}\right]-k_{-2}\left[\mathrm{LH}^{-}\right]\left[\mathrm{H}^{+}\right]+k_{1}[\mathrm{LH}]
\end{aligned}
$$

$$
\begin{aligned}
& -k_{-1}\left[\mathrm{~L}^{-}\right]\left[\mathrm{H}^{+}\right]+k_{w}\left[\mathrm{H}_{2} \mathrm{O}\right]-k_{-w}\left[\mathrm{H}^{+}\right]\left[\mathrm{OH}^{-}\right], \\
\frac{\partial\left[\mathrm{OH}^{-}\right]}{\partial t}= & D \frac{\partial^{2}\left[\mathrm{OH}^{-}\right]}{\partial x^{2}}+k_{w}\left[\mathrm{H}_{2} \mathrm{O}\right]-k_{-w}\left[\mathrm{H}^{+}\right]\left[\mathrm{OH}^{-}\right] .
\end{aligned}
$$

Here and below, the rate constants of forward reactions (1), (2), and (3) are specified as $k_{2}, k_{1}$, and $k_{w}$, respectively. Similarly, the rate constants of reverse processes are denoted by the respective negative subscripts.

Simple linear operations, applied to (4), yield the relationships that contain no kinetic terms:

$$
\begin{aligned}
\frac{\partial c_{\mathrm{ac}}}{\partial t} & =D \frac{\partial^{2} c_{\mathrm{ac}}}{\partial x^{2}} \\
\frac{\partial c_{\mathrm{H}}}{\partial t} & =D \frac{\partial^{2} c_{\mathrm{H}}}{\partial x^{2}}
\end{aligned}
$$

where the total (analytical) concentration of acid

$$
c_{\mathrm{ac}}=\left[\mathrm{LH}_{2}\right]+\left[\mathrm{LH}^{-}\right]+\left[\mathrm{L}^{2-}\right]
$$

and the total concentration of proton donors and acceptors

$$
c_{\mathrm{H}}=2\left[\mathrm{LH}_{2}\right]+\left[\mathrm{LH}^{-}\right]+\left[\mathrm{H}^{+}\right]-\left[\mathrm{OH}^{-}\right]
$$

A more extensive analysis shows that similar equations are obtained in the case of systems containing any number of proton donors.

Prior to further dealing with the problem, some points should be discussed. Firstly, it should be noted that the same effective diffusion coefficient $D$ is attributed to all species, despite the fact that the individual mobilities of various particles can be rather different. Previously, it has been shown [5-7] that such an assumption is admissible in the case of labile systems, that is when the abovementioned chemical interactions are fast enough. Specifically, Kačena and Matoušek [5] elaborated the mechanism that gives rise to the apparent equalization of diffusion coefficients.

The second remark concerns the total concentrations that are defined by (7) and (8). Whereas $c_{\mathrm{ac}}$ has a clear physical meaning, the second one, $c_{\mathrm{H}}$, looks as made-up quantity. Moreover, $c_{\mathrm{H}}$ can turn negative at sufficiently high $\mathrm{pH}$, but then the hydrogen evaluation involving hydronium ions becomes unfeasible. Notice that a similar approach, constructed in such a way and involving $c_{\mathrm{H}}$ values, was successfully used for analysis of electrochemical processes occurring in the systems containing metal complexes and protonated ligands [4].

The certain gradient of $c_{\mathrm{H}}$ developed in the diffusion layer is determined by the relationship following from the first Fick's law:

$$
i=-\left.n F D \frac{\partial c_{\mathrm{H}}}{\partial x}\right|_{x=0}
$$

where $n=1$ is a charge number of the electrode reaction.

For as much as an acid itself is assumed to be an electrically inactive substance, the $c_{\mathrm{ac}}$ quantity should be constant over the entire range of diffusion layer. Solution of 
the differential equation (6) in combination with common initial conditions and boundary condition (9) yields the result:

$$
\Delta c_{\mathrm{H}}(t)=-\frac{1}{n F \sqrt{\pi D}} \int_{0}^{t} \frac{i(t-u)}{\sqrt{u}} \Psi(u) d u,
$$

where $\Delta c_{\mathrm{H}}(t)$ is the difference between the bulk and surface concentrations of proton donors and $u$ is an auxiliary variable having dimension of time. Thus, the variable $t$ in $i(t)$-function should be replaced by $(t-u)$ when $(10)$ is used. The function

$$
\Psi(u)=1+2 \sum_{m}^{\infty}(-1)^{m} \exp \left(-\frac{m^{2} \delta^{2}}{D u}\right)
$$

accounts for the existence of $\delta$-thick diffusion layer. Hence, the foregoing shows that the variations of $c_{\mathrm{H}}$ are rather similar to those established for the oxidized form in the case of simple redox processes (see, e.g., [2]).

The next problem consists in determination of the interrelation between the current density $i$ and overvoltage $\eta$ (or electrode potential $E$ ). This can be performed by means of the proper modification of Butler-Volmer equation that also contains the surface concentrations of oxidant and reductant as well as kinetic parameters of the charge-transfer step. Notice that the above equations (5)-(10) operate with total concentrations only. Then, to determine the amount of concrete particles, the certain interrelations between concentrations of different species should be formulated. This can be done in a simple way, when chemical interactions are sufficiently fast. Then, it is reasonable to suppose that the deviations from chemical equilibria are negligible and the well-known material balance equations, involving respective equilibrium constants, may be used for estimation of bulk or surface concentrations of every component. Otherwise, when the above assumption is not acceptable, (5) and (6) lose their significance and initial equations (4) involving kinetic terms should be solved.

\section{Results and Discussion}

Voltammetric experiments were carried out with solutions containing different organic acids (OA) and an excess of supporting electrolyte. The presence of the latter substance made it possible to minimize the effect of migration on the mass-transport processes. Besides, some data were obtained with similar solutions containing $\mathrm{Cu}(\mathrm{II})$. The acids under study are listed in Table 1; their symbols $\mathrm{LH}$ or $\mathrm{LH}_{2}$ render a number of mobile protons $\left(\mathrm{H}^{+}\right.$ions) that can be splitted out in acidic water solutions. Hereinafter, equilibrium characteristics of dissociation processes involving $\mathrm{OA}$ are presented quantitatively by cumulative stability constants (reciprocals of dissociation constants) defined as follows:

$$
\begin{aligned}
& \beta_{1}=\frac{[\mathrm{LH}]}{\left[\mathrm{L}^{-}\right]\left[\mathrm{H}^{+}\right]}, \\
& \beta_{2}=\frac{\left[\mathrm{LH}_{2}\right]}{\left[\mathrm{L}^{-}\right]\left[\mathrm{H}^{+}\right]^{2}},
\end{aligned}
$$

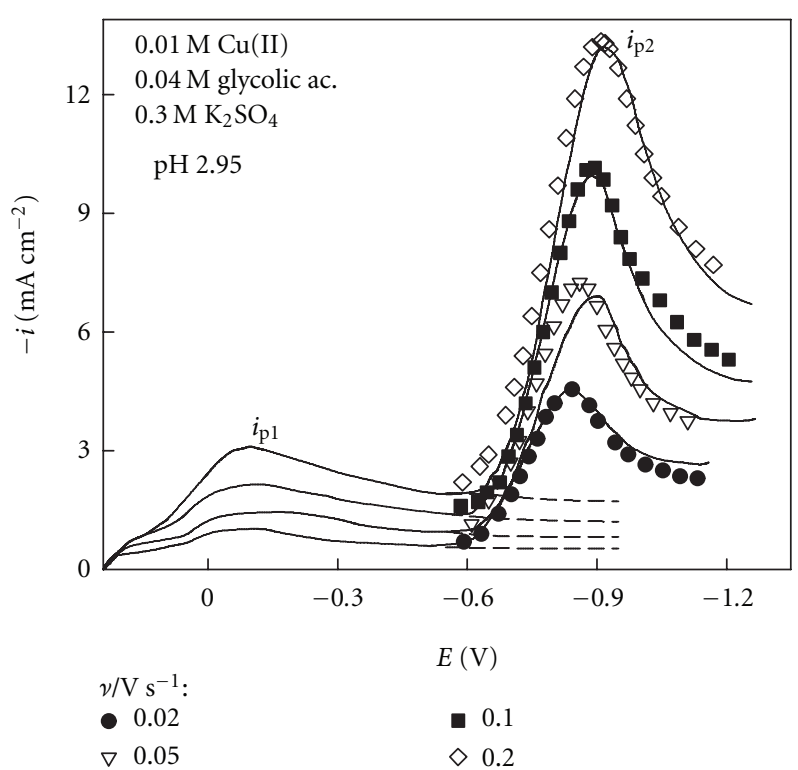

Figure 1: Comparison of voltammetric data obtained at different potential sweep rates $v$ for $\mathrm{Cu}(\mathrm{II})$-containing (solid lines) and $\mathrm{Cu}$ (II)-free (symbols) solutions. The latter data are superimposed on the limiting currents of $\mathrm{Cu}(\mathrm{II})$ reduction (dotted lines).

(in the case of dibasic acid $\mathrm{LH}_{2}$, the stability of intermediate anion $\mathrm{LH}^{-}$is also characterized by the relationship similar to (12)).

Due to a sufficiently high difference between the standard potentials of $\mathrm{Cu} \mid \mathrm{Cu}^{2+}$ and $\mathrm{H}_{2} \mid \mathrm{H}^{+}$electrodes, partial processes of $\mathrm{Cu}(\mathrm{II})$ reduction and hydrogen evolution are well-separated, unless very stable $\mathrm{Cu}(\mathrm{II})$ complexes are formed. This can be seen from a typical example shown in Figure 1. Experimental voltammograms contain two welldefined maxima that are indicative of two different cathodic processes. The first current peak $\left(i_{\mathrm{p} 1}\right)$ observed at a relatively low cathodic polarization $\left(E_{\mathrm{p} 1} \approx-0.1 \mathrm{~V}\right)$ results from $\mathrm{Cu}(\mathrm{II})$ reduction. A further increase in cathodic polarization gives rise to the second process with a distinctive current peak $\left(i_{\mathrm{p} 2}\right)$ observed at $E_{\mathrm{p} 2} \approx-0.9 \mathrm{~V}$. This maximum may be conditioned by different reasons, such as $\mathrm{Cu}_{2} \mathrm{O}$ reduction or hydrogen evolution [12]. EQCM investigations of $\mathrm{Cu}(\mathrm{II})$-glycolic acid solutions have shown [12] that no extra changes in copper electrode mass are observed in this region. Moreover, similar current peaks are also observed in $\mathrm{Cu}$ (II)-free solutions. The voltammograms obtained in the latter case and brought to the level of partial $\mathrm{Cu}$ (II) reduction current (dotted lines in Figure 1) coincide sufficiently well with the data recorded in the presence of $\mathrm{Cu}(\mathrm{II})$. This effect, as well as large difference between $E_{\mathrm{p} 1}$ and $E_{\mathrm{p} 2}$, gives grounds to suppose that the two partial processes may be analyzed independently. The limiting current of $\mathrm{Cu}(\mathrm{II})$ reduction, specified by the relationship

$$
i_{\lim }=\frac{n F D}{\delta} c_{\mathrm{Cu}(\mathrm{II})},
$$

could serve as the base line for hydrogen evolution. In this connection, it should be said, that the thickness, $\delta$, of 
TABLE 1: Selected stability constants of organic acids.

\begin{tabular}{|c|c|c|c|c|c|}
\hline \multirow{2}{*}{ Substance } & \multirow{2}{*}{ Formula } & \multirow{2}{*}{ Symbol } & \multicolumn{2}{|c|}{ Stability constant } & \multirow{2}{*}{ Ref. } \\
\hline & & & $\log \beta_{1}$ & $\log \beta_{2}$ & \\
\hline Glycolic acid & $\mathrm{HO}-\mathrm{CH}_{2}-\mathrm{COOH}$ & LH & 3.63 & & {$[8,9]$} \\
\hline Malic acid & $\mathrm{HOOC}-\mathrm{CH}_{2}-(\mathrm{CH}-\mathrm{OH})-\mathrm{COOH}$ & $\mathrm{LH}_{2}$ & 4.24 & 7.24 & {$[8,9]$} \\
\hline Tartaric acid & HOOC- $(\mathrm{CH}-\mathrm{OH})_{2}-\mathrm{COOH}$ & $\mathrm{LH}_{2}$ & 4.26 & 7.4 & {$[8-10]$} \\
\hline Gluconic acid & $\mathrm{HO}-\mathrm{CH}_{2}-(\mathrm{CH}-\mathrm{OH})_{4}-\mathrm{COOH}$ & $\mathrm{LH}$ & 3.7 & & {$[11]$} \\
\hline
\end{tabular}

the Nernst-type diffusion layer (that develops under the natural convection conditions) depends on the potential sweep rate $\nu$. Voltammetric investigations of $\mathrm{Fe}(\mathrm{CN})_{6}^{4-} / \mathrm{Fe}(\mathrm{CN})_{6}^{3-}$ redox system have shown [13] that the empirical condition $\delta \sqrt{\nu} \approx$ const is obeyed in this case. According to the results of our further investigations, this relation is also valid for $\mathrm{Cu}$ (II) systems containing OA. The procedures used for estimation of $\delta$ values are described elsewhere [13].

Solution $\mathrm{pH}$ should be mentioned in the first place as a factor which determines the rate of hydrogen evolution. This can be clearly seen from the typical data shown in Figure 2. Naturally, current density significantly falls with increase in solution $\mathrm{pH}$, that is, when the concentration of hydronium ions decreases. However, when $\mathrm{pH}$ is kept constant, the rate of the process under discussion increases with the total concentration of acid $\left(c_{\mathrm{ac}}\right)$. This effect will be analyzed below in more detail. Finally, the supporting electrolyte plays a part in these processes: the height of the second current peak decreases gradually when sulphate is replaced by perchlorate (Figure 3). Revealed experimental phenomena imply that not only $\mathrm{LH}^{-}$or $\mathrm{LH}_{2}$ but also $\mathrm{HSO}_{4}^{-}$should be treated as a proton donor and should be included into (8).

The composition of solutions was calculated using modified material balance equations (7) and (8):

$$
\begin{gathered}
c_{\mathrm{ac}}=\left[\mathrm{L}^{2-}\right]\left(1+\beta_{1}\left[\mathrm{H}^{+}\right]+\beta_{2}\left[\mathrm{H}^{+}\right]^{2}\right), \\
c_{\mathrm{H}}=\left[\mathrm{H}^{+}\right]\left(1+\beta_{1}\left[\mathrm{~L}^{2-}\right]+2 \beta_{2}\left[\mathrm{~L}^{2-}\right]\left[\mathrm{H}^{+}\right]\right. \\
\left.+K_{\mathrm{slf}}\left[\mathrm{SO}_{4}^{2-}\right]-\left[\mathrm{OH}^{-}\right]\right)
\end{gathered}
$$

and the expression written for total sulphate concentration:

$$
c_{\text {slf }}=\left[\mathrm{SO}_{4}^{2-}\right]\left(1+K_{\text {slf }}\left[\mathrm{H}^{+}\right]\right) .
$$

Stability constants $\beta_{1}$ and $\beta_{2}$ are listed in Table 1; a similar characteristic of hydrosulfate, $K_{\text {slf }}=30$, was taken from a handbook $[8,9]$ as best-matched to the ionic strength of the solutions under discussion. To obtain the concentration of hydronium ions from $\mathrm{pH}$ measurements, the activity coefficient $\gamma_{\mathrm{H}}=0.7$ was used. It was obtained by empirical equations given in $[14,15]$. The concentration of $\mathrm{OH}^{-}$ions was obtained from the ion product of water. An example of the results obtained is given in Table 2 . It can be seen that the amount of hydronium ions is not great in the solutions containing a large excess of sulphate. Thus, LH molecules and hydrosulphate anions are the species that should be related to predominating proton donors.

Most of the experimental data obtained are typical of every OA under investigation. Therefore, to minimize
TABLE 2: Distribution of different species in the solutions containing $0.02 \mathrm{M}$ of gluconic acid and $0.5 \mathrm{M}$ of $\mathrm{Na}_{2} \mathrm{SO}_{4}$ as a supporting electrolyte.

\begin{tabular}{cccccc}
\hline $\mathrm{pH}$ & $\begin{array}{c}\mathrm{H}_{3} \mathrm{O}^{+} \\
(\mathrm{mM})\end{array}$ & $\begin{array}{c}\mathrm{L}^{-} \\
(\mathrm{mM})\end{array}$ & $\begin{array}{c}\mathrm{LH} \\
(\mathrm{mM})\end{array}$ & $\begin{array}{c}\mathrm{HSO}_{4}^{-} \\
(\mathrm{mM})\end{array}$ & $\begin{array}{c}c_{\mathrm{H}} \\
(\mathrm{mM})\end{array}$ \\
\hline 2.0 & 14.3 & 0.28 & 19.7 & 150 & 184 \\
2.5 & 4.51 & 0.85 & 19.1 & 59.7 & 83.3 \\
3.0 & 1.43 & 2.5 & 17.6 & 20.5 & 39.5 \\
4.0 & 0.14 & 11.6 & 8.3 & 2.16 & 10.6 \\
\hline
\end{tabular}

the size of this paper, we present below freely selected results obtained for either system. According to them, current peaks (that further are simply symbolized as $i_{\mathrm{p}}$ ) increase with the potential sweep rate $\nu$, and linear dependences between $i_{\mathrm{p}}$ and $\sqrt{\nu}$ are observed (Figures 4 and 5). The slopes of these lines, $S$, increase when the acidity of solutions grows $(\mathrm{pH}$ falls) and the acid concentration is increased. The observed phenomena are consistent with the aforestated assumptions concerning the mechanism of electrode reactions. Since the position of current peaks depends on $v$ (Figures 1 and 2 and the data given below), the cathodic process should be treated as irreversible. Then, the simplified kinetic equation is valid for sufficiently high overvoltages:

$$
\log i_{\text {norm }}=\log i_{0}-\frac{\alpha n F}{2.303 R T} \eta,
$$

where $i_{0}$ is an exchange current density, $\alpha$ is a cathodic charge-transfer coefficient, overvoltage $\eta=E-E_{\text {eq }}$, and $E_{\text {eq }}$ is equilibrium potential. Normalized current density is defined by the relationship:

$$
i_{\text {norm }}=\frac{|i|}{\left[\mathrm{H}^{+}\right]_{s} /\left[\mathrm{H}^{+}\right]_{b}},
$$

where subscripts $s$ and $b$ denote the surface and bulk concentrations of hydronium ions. Once the latter two quantities are determined, linear normalized Tafel plots (NTP) can be obtained.

Procedures of data treatment might be as follows. Firstly, special integration of experimental voltammograms, transformed into $i-t$ functions, is performed (see (10)) and $\Delta c_{\mathrm{H}}$ quantities, as $E$ functions, are obtained (Figure 6). The latter operation needs a certain diffusion coefficient to be used. Traditionally, it can be obtained from RDE data and tested for the condition according to which the limiting $\Delta c_{\mathrm{H}}$ value (see plateau in Figure 6) cannot exceed the bulk concentration of proton donors. 


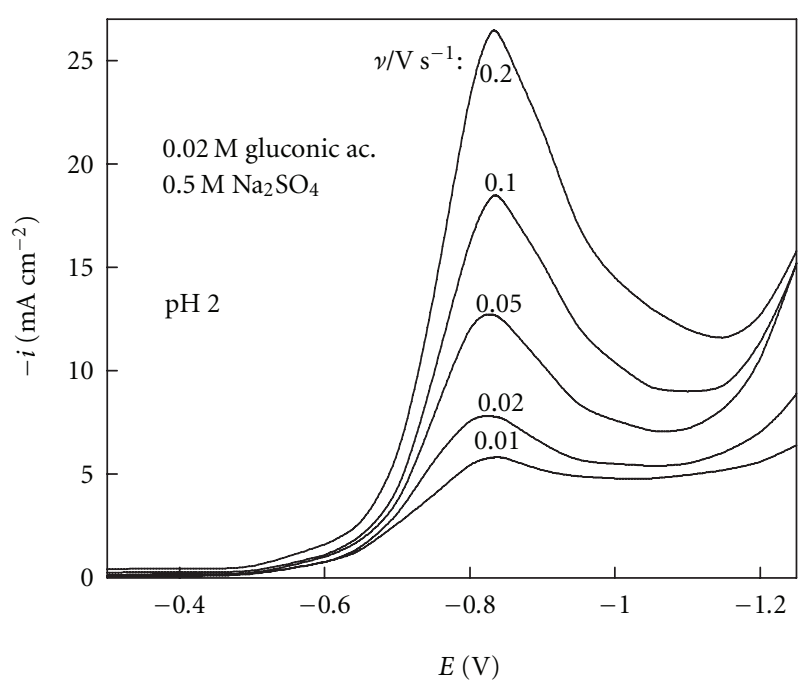

(a)

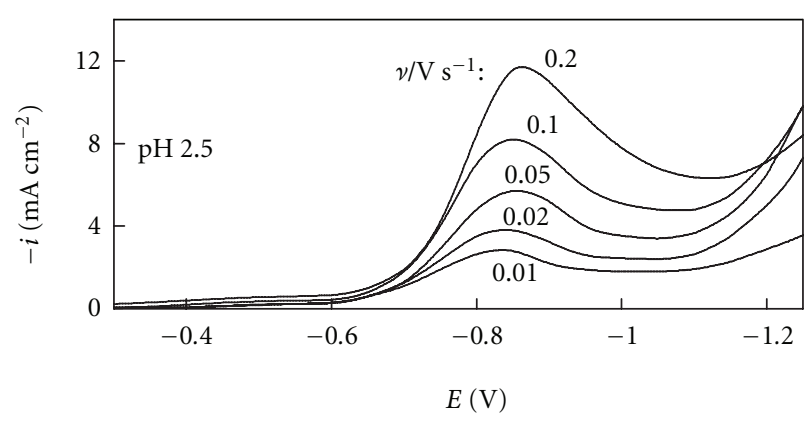

(b)

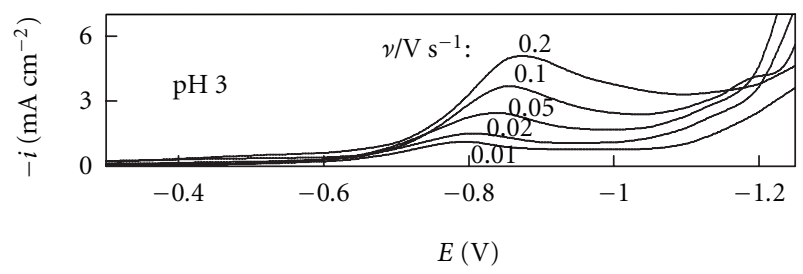

(c)

Figure 2: Voltammograms obtained for $0.02 \mathrm{M}$ gluconic acid solutions containing $0.5 \mathrm{M} \mathrm{Na}_{2} \mathrm{SO}_{4}$ at different $\mathrm{pH}$. Potential sweep rates are indicated at the respective curves.

The second step consists, in determination, of distribution of proton donors at the electrode surface under cathodic polarization conditions. For this purpose, (15)-(17) are used. The surface value of total concentration of proton donors, $c_{\mathrm{Hs}}$, is decreased from the bulk value $c_{\mathrm{H}}$ (initial state) to zero (limiting current region) keeping $c_{\mathrm{ac}}$ and $c_{\mathrm{slf}}$ constant. It should be emphasized that the surface concentration of the electrically active substance (hydronium ions) does not fall to zero in contrast to common redox processes (see (8) or (16)). In the absence of proton donors, a neutral medium is created at the electrode surface $\left(\left[\mathrm{H}^{+}\right]_{s}=\left[\mathrm{OH}^{-}\right]_{s}\right)$, otherwise alkalization occurs. An example of the data obtained is shown in Figure 7.

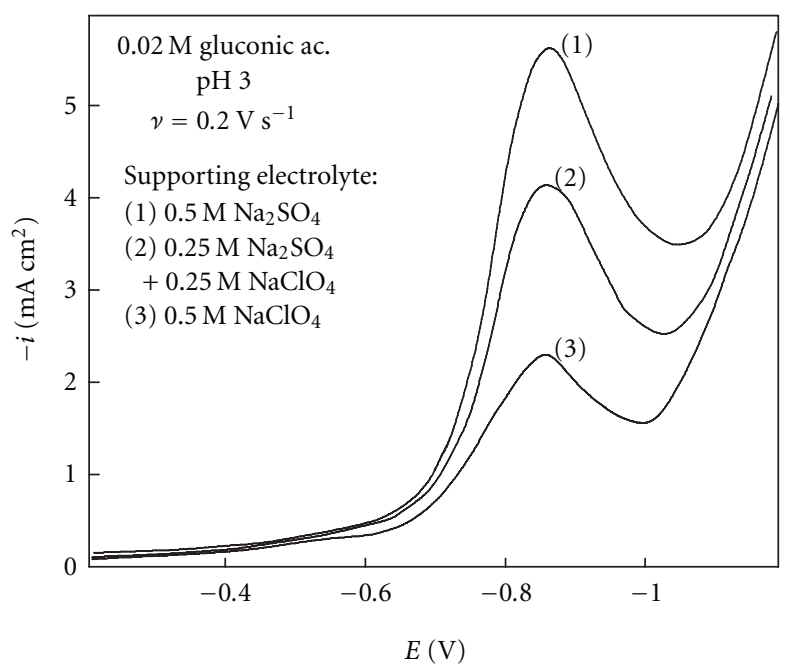

FIgUre 3: Comparison of voltammetric data obtained at $v=$ $0.2 \mathrm{~V} \mathrm{~s}^{-1}$ for $0.02 \mathrm{M}$ gluconic acid solutions containing different supporting electrolytes as indicated.

Notice that the same data can be presented as $E$ functions, since the interrelation between $c_{\mathrm{Hs}}$ and $E$ is easily obtained from Figure 6. This makes it possible to assign the value of $\left[\mathrm{H}^{+}\right]_{s}$ at any potential of voltammograms and to transform them into normalized Tafel plots. Some results of the procedures performed are shown in Figure 8. The data obtained at different $v$ are very close and can be approximated by one average NTP. The kinetic parameters of charge-transfer process obtained by (18) are shown in Figure 8 and listed in Table 3. Though the equilibrium potential of $\mathrm{H}^{+} \mid \mathrm{H}_{2}$ electrode is uncertain in $\mathrm{H}_{2}$-free solutions, the exchange of current density, named as "effective", was determined by extrapolation of NTP to the theoretical quantity defined by the relationship:

$$
E_{\text {eq }}=-\frac{2.303 R T}{F} \mathrm{pH} .
$$

Low $i_{0}^{\text {eff }}$ values are responsible for a high overvoltage of hydrogen evolution: current densities are low over a wide initial range of potentials. The rise of voltammograms is observed at rather negative potentials ranging up to $-0.6 \mathrm{~V}$.

LPS voltammograms possess characteristic maxima, the coordinates of which are convenient to use in the kinetic analysis. At present, relationships for $i_{\mathrm{p}}$ and $E_{\mathrm{p}}$ are available for different mechanisms, including the case of simple redox processes that are controlled by the charge transfer and diffusive mass transport [1-3]. The latter case is somewhat similar to that presented here, but one peculiarity needs to be considered. When a simple redox process occurs, both current density and electrode potential depend on the concentration of the same electroactive species. However, the case under consideration offers the following distinctive feature: the electrode potential is determined by $\left[\mathrm{H}^{+}\right]$, whereas the current density is determined by the total flux of all proton donors and is dependent on $c_{\mathrm{H}}$. Keeping this in mind, we reasoned that the certain modification of common 
TABLE 3: Equilibrium characteristics of OA solutions and the kinetic parameters of hydrogen evolution.

\begin{tabular}{|c|c|c|c|c|c|c|c|c|c|}
\hline \multirow{2}{*}{$\mathrm{OA}$} & \multirow{2}{*}{$c_{\mathrm{ac}}(\mathrm{mM})$} & \multirow{2}{*}{$c_{\mathrm{slf}}(\mathrm{M})$} & \multirow{2}{*}{$\mathrm{pH}$} & \multirow{2}{*}{$c_{\mathrm{H}}(\mathrm{mM})$} & \multirow{2}{*}{$10^{6} \mathrm{D}\left(\mathrm{cm}^{2} \mathrm{~s}^{-1}\right)$} & \multirow{2}{*}{$\alpha$} & \multirow{2}{*}{$i_{0}^{\mathrm{eff}}\left(\mu \mathrm{Acm}^{-2}\right)$} & \multicolumn{2}{|c|}{$S\left(\mathrm{mAcm}^{-2} \mathrm{~V}^{-05} \mathrm{~s}^{0.5}\right)$} \\
\hline & & & & & & & & Equation (21) & exper. \\
\hline Gluconic & 40 & 0.3 & 2.95 & 43.3 & 6.8 & 0.61 & 10 & 26.9 & 26.7 \\
\hline Malic & 40 & 0.3 & 3.0 & 76.2 & 3.1 & 0.64 & 8 & 32.7 & 33.6 \\
\hline Tartaric & 40 & 0.3 & 2.9 & 85.0 & 2.1 & 0.64 & 9 & 30.1 & 30.7 \\
\hline Gluconic & 20 & 0.5 & 3.0 & 39.5 & 1.5 & 0.60 & 8 & 11.4 & 11.2 \\
\hline
\end{tabular}

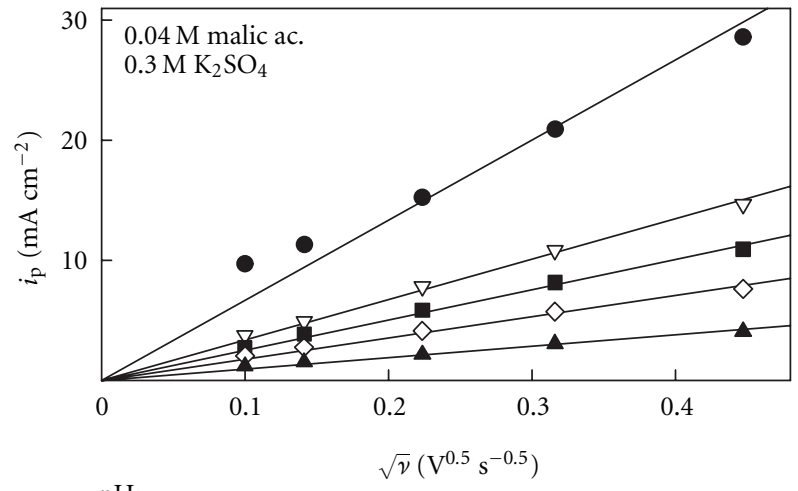

pH:

- 2.2

$\diamond 3.9$

$\triangle 4.5$

- 3.5

(a)

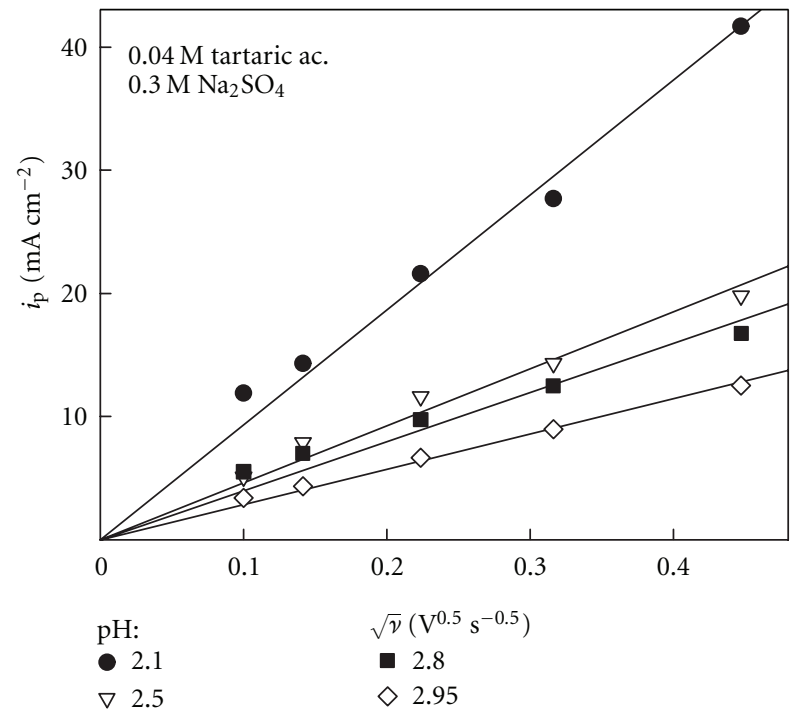

(b)

FIGURE 4: Peak current densities versus $\sqrt{\nu}$ obtained at different $\mathrm{pH}$ for $0.04 \mathrm{M}$ malic and tartaric acid solutions.

relationships, with $c_{\mathrm{H}}$ in place of $c$, is permissible. Then, the current peak expression takes the following form:

$$
i_{\mathrm{p}}=0.282 n F \sqrt{\frac{\pi F}{R T} \alpha \nu D c_{\mathrm{H}}} .
$$

To check the correctness of this equation, the slopes $S \equiv$ $\partial i_{\mathrm{p}} / \partial \sqrt{\nu}$ of linear " $i_{\mathrm{p}}-\sqrt{\nu}$ " plots were analyzed with the

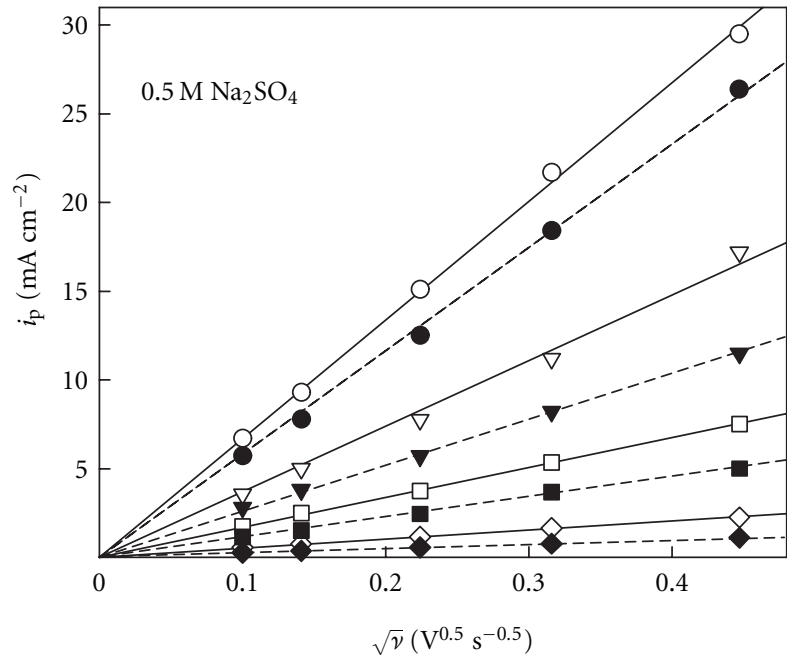

$\begin{array}{lll}\text { pH: } & & \text { Gluconic ac. } \\ \bigcirc 2 & \square 3 & -0.05 \mathrm{M} \\ \nabla 2.5 & \diamond 4 & --0.02 \mathrm{M}\end{array}$

Figure 5: Peak current densities versus $\sqrt{\nu}$ obtained at different $\mathrm{pH}$ for $0.02 \mathrm{M}$ (dashed lines) and $0.05 \mathrm{M}$ (solid lines) gluconic acid solutions.

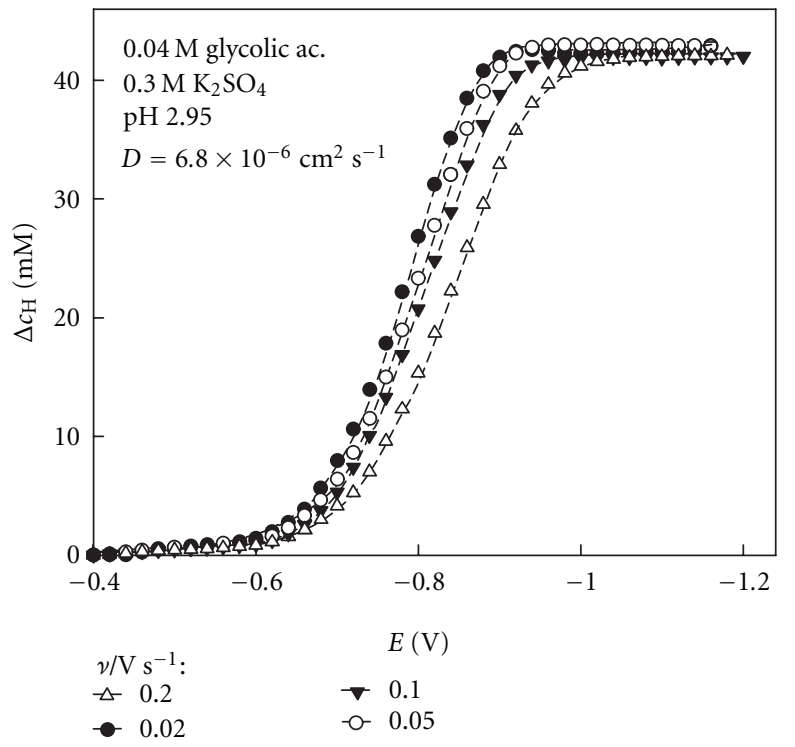

FIGURE 6: Changes in the surface concentration of proton donors calculated by (10) from voltammetric data obtained for $0.04 \mathrm{M}$ glycolic acid solution at different potential sweep rates. 


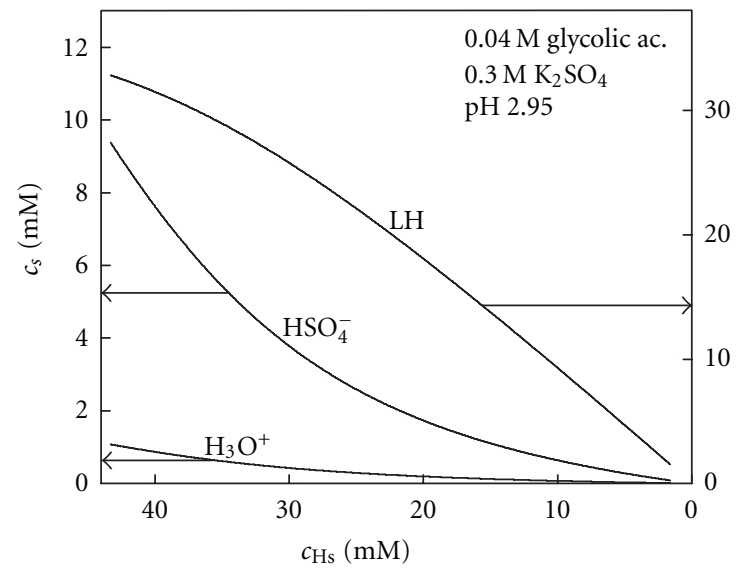

FIgURE 7: Distribution of proton donors at the electrode surface during the electrolysis of $0.04 \mathrm{M}$ glycolic acid solution. Cathodic current density increases from left to right.

values of $\alpha, D$, and $c_{\mathrm{H}}$ taken from the foregoing analysis. According to the results obtained, experimentally determined slopes are in a good agreement with the quantities that follow from (21) (Table 3).

It can be also seen from these data that the kinetic parameters of the charge-transfer step, obtained for different $\mathrm{OA}$, are quite similar. Then, according to (21), the linear interrelation between $S$ and $c_{\mathrm{H}}$ should be governed only by the equilibrium and mass transport parameters. In this regard, all experimental data, obtained for different OA solutions at various $c_{\mathrm{ac}}$ and $\mathrm{pH}$, were generalized and collected in Figure 9. It can be seen that a satisfactory approximation can be performed by single general regression line. The results obtained show that the processes of hydrogen evolution, proceeding in the systems under consideration, possess very similar features, and the same theoretical model is acceptable for their description.

It is of interest to view the data concerning the position of current maxima in the scale of potentials. The model presented above supposes a linear dependence between $E_{\mathrm{p}}$ and $\log v$, the slope of which is determined by the relationship:

$$
\frac{\partial E_{\mathrm{p}}}{\partial \log \nu}=-\frac{2.303 R T}{2 \alpha F} .
$$

This regularity is consistent with the most experimental data obtained for moderately acidic $\mathrm{Cu}$ (II)-free solutions. For instance, the average slope of lines, presented in the lower part of Figure 10, is ca $50 \mathrm{mV} /$ decade; then, the value $\alpha \approx 0.6$ that follows from (22) is in agreement with the experimental data listed in Table 3. However, $E_{\mathrm{p}}$ ceases to depend on $v$ in more acidic ( $\mathrm{pH}$ 2.0) $0.02 \mathrm{M}$ gluconic acid solutions, this is indicative of the reversible character of the chargetransfer process. When $\mathrm{pH}$ of such solutions was increased, a tendency for a certain increase in $\partial E_{\mathrm{p}} / \partial \log v$ magnitudes was observed, but this was not the case for more concentrated $(0.05 \mathrm{M})$ solutions.

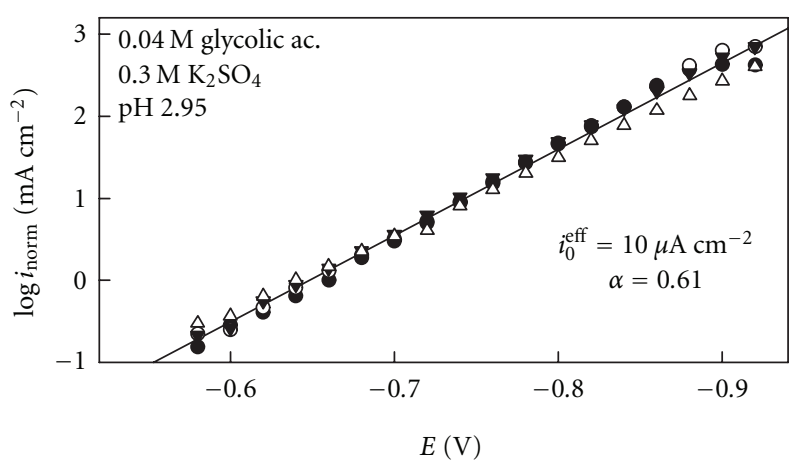

(a)

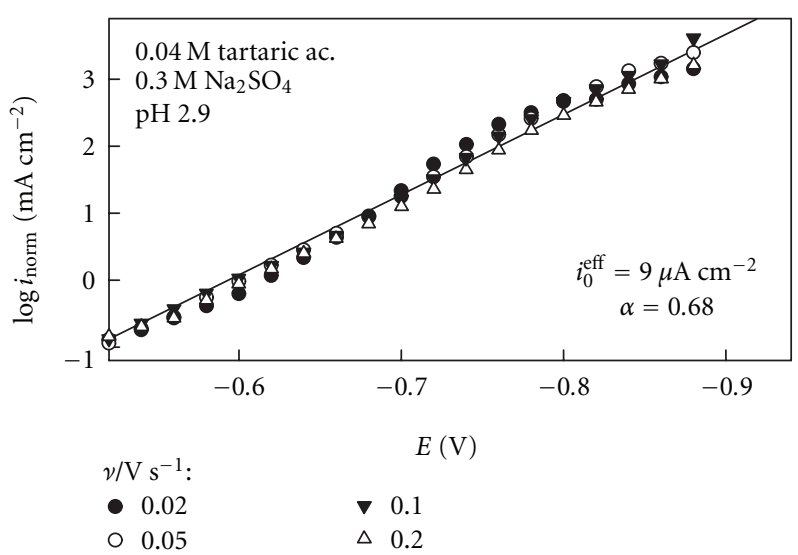

(b)

FIGURE 8: Normalized Tafel plots obtained at different potential sweep rates for $0.04 \mathrm{M}$ glycolic (a) and tartaric (b) acid solutions. Indicated kinetic parameters are calculated from general regression lines.

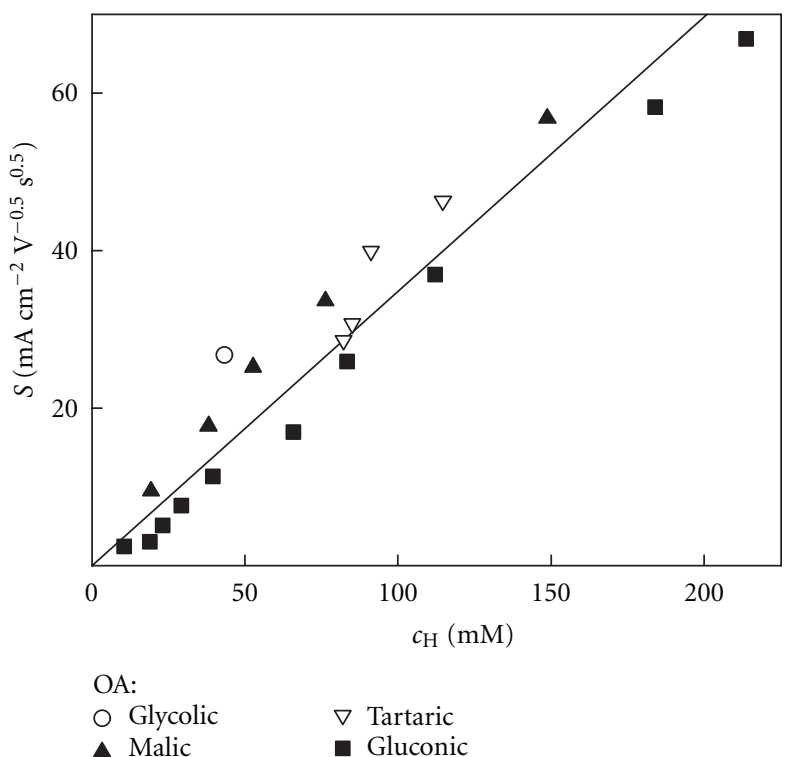

FIGURE 9: Experimental slopes $S \equiv \partial i_{\mathrm{p} 2} / \partial \sqrt{\nu}$ versus total concentration of proton donors. Summation of the data obtained for different solutions at $2.5<\mathrm{pH}<4.0$. 


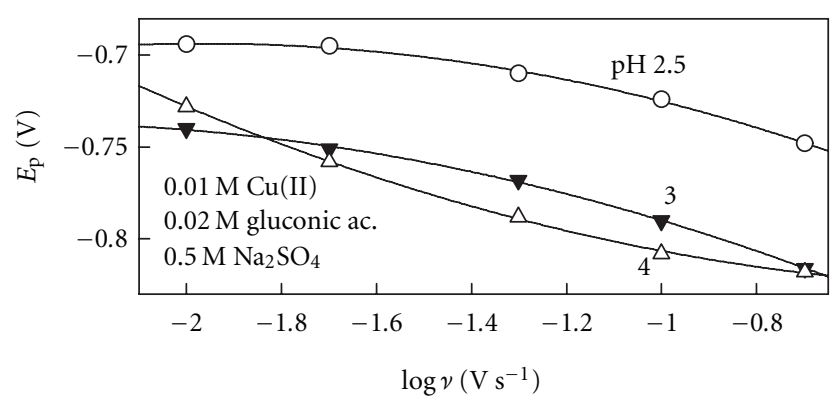

(a)

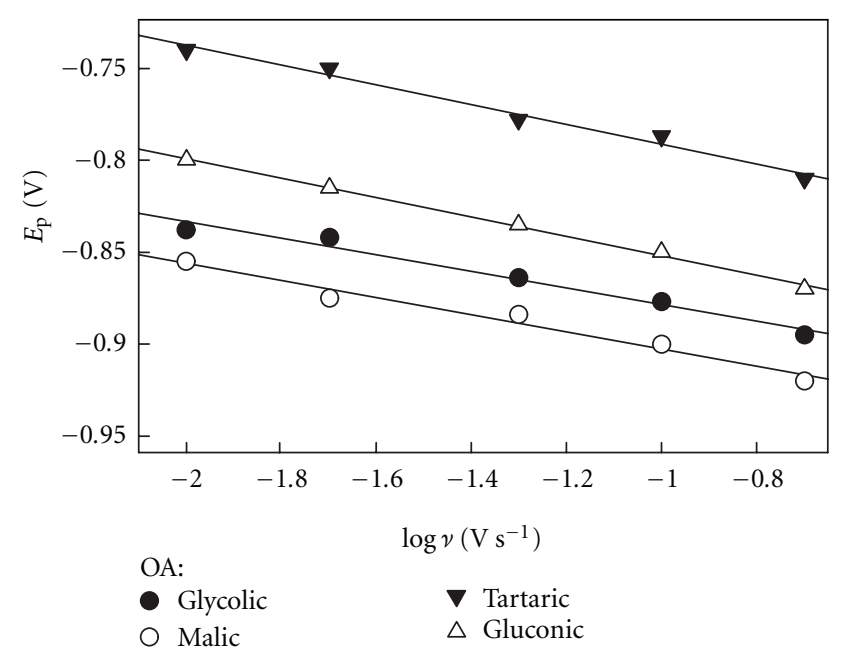

(b)

Figure 10: Dependencies of peak potentials on potential sweep rate presented in semilogarithmic coordinates. The data are obtained for $0.02 \mathrm{M}$ gluconic acid solutions containing $\mathrm{Cu}$ (II) (a) and for $\mathrm{Cu}$ (II)free solutions (b), the composition of which is given in the Table 3.

Nonlinear $E_{\mathrm{p}}$ dependences on $\log v$ are observed in the case of $\mathrm{Cu}(\mathrm{II})$-containing solutions (Figure 10(a)). It is necessary to point out that the situation at the electrode surface is not exactly the same as that in identical $\mathrm{Cu}(\mathrm{II})$ free solutions containing the same $c_{\mathrm{ac}}$ and $\mathrm{pH}$. As what was stated above, hydrogen evolution starts in the region of limiting current, where the surface concentration of $\mathrm{Cu}(\mathrm{II})$ approaches zero but $c_{\mathrm{ac}}$ and $c_{\mathrm{H}}$ remain unchanged. However, a certain amount of OA anions is released from the reduced $\mathrm{Cu}(\mathrm{II})-\mathrm{OA}$ complexes. This results in the shift of chemical equilibria and in the relevant increase in surface $\mathrm{pH}$. Again, simultaneous deposition of copper can also modify the properties of original coatings that were prepared as working electrodes (see Section 2).

The kinetic parameters listed in Table 3 have been determined using not only experimental, but also the literature data. It is common knowledge that stability constants expressed in concentration terms depend on the ionic strength of solutions and on the nature of supporting electrolyte. Unfortunately, data given in different handbooks concern, as a rule, perchlorate or nitrate media and the certain problems arise when fitting such data for sulphate media. Therefore, the reliability of the parameters established here also depends on the reliability of the data selected from the literature. Nevertheless, it can be stated that the kinetic parameters of hydrogen evolution, occurring on the same copper substrate, are very similar in the case of all the systems under investigation. Organic acids seem to be of minor importance for the charge-transfer process and act in general as sufficiently labile proton donors.

\section{Conclusions}

The CE mechanism of hydrogen evolution occurring in organic acids (OAs) solutions was analyzed invoking the 2 nd Fick's law equations supplemented by terms that account for chemical interactions between diffusing particles. OA are considered as components that are capable of releasing hydrated protons (hydronium anions) taking part in the charge-transfer step. Simple equations containing no kinetic terms were obtained for total concentration of proton donors and acceptors, $c_{\mathrm{H}}$. When the dissociation of OA is sufficiently fast, the surface concentrations of species can be obtained from the material balance equations involving the stability constants of proton donors.

Linear potential sweep (LPS) voltammetry was applied to study the kinetics of hydrogen evolution in the solutions containing glycolic, malic, tartaric, and gluconic acids. Current peaks observed on LPS voltammograms are in a linear dependence on $\sqrt{\nu}$ ( $\nu$ is the potential sweep rate). They obey well-known relationships obtained for simple redox processes, provided that the concentration of oxidant is treated as $c_{\mathrm{H}}$.

Determination of surface concentrations as current density functions makes it possible to transform LPS voltammograms into linear Tafel plots normalized with respect to the surface concentration of hydronium ions. Similar kinetic parameters $\left(\alpha \approx 0.62\right.$ and $\left.i_{0} \approx 10 \mu \mathrm{Acm}^{-2}\right)$ ) obtained at $\mathrm{pH}$ 3 for all OA solutions indicate that the nature of OA has no noticeable influence on the charge-transfer process.

\section{References}

[1] D. D. Macdonald, Transient Techniques in Electrochemistry, Plenum Press, New York, NY, USA, 1977.

[2] A. J. Bard and L. R. Faulkner, Electrochemical Methods: Fundamentals Applications, John Wiley \& Sons, New York, NY, USA, 2nd edition, 2001.

[3] Z. Galus, Fundamentals of Electrochemical Analysis, John Wiley \& Sons, New York, NY, USA, 2nd edition, 1994.

[4] A. Survila, Electrode Processes in Systems of Labile Metal Complexes, Mokslas, Vilnius, Lithuania, 1989.

[5] V. Kačena and L. Matoušek, "Proteins and aminoacids. XVI-II. The effect of electrolytes on proteins," Collection of Czechoslovak Chemical Communications, vol. 18, p. 294, 1953.

[6] F. Hilbert, Die elektrolytische abscheidung von eisen und wasserstoff, Habilitations, Schrift Universität Graz, 1969.

[7] Y. Miyoshi and W. J. Lorenz, "Zum Protonentransport in schwefelsauren Lösungen," Berichte der Bunsengesellschaft für Physikalische Chemie, vol. 74, no. 4, pp. 412-416, 1970.

[8] L. G. Sillen and A. E. Martel, Stability Constants Metal-Ion Complexes, no. 17, Chemical Society, London, UK, 1964.

[9] L. G. Sillen and A. E. Martel, Stability Constants Metal-Ion Complexes, no. 25, Chemical Society, London, UK, 1971. 
[10] E. P. Serjeant and B. Dembsey, Ionisation Constants of Organic Acids in Aqueous Solutions, Pergamon Press, Oxford, UK, 1979.

[11] "Gluconic acid and derivatives," SIDS Initial Assessment Report for SIAM 18, SIAM, Paris, France, 2004.

[12] A. Survila, A. Survilienė, S. Kanapeckaitè et al., "Oxide layers developed on copper solutions containing electrodes in $\mathrm{Cu}$ (II) ligands," Journal of Electroanalytical Chemistry, vol. 582, no. 12, pp. 221-229, 2005.

[13] A. Survila, P. V. Stasiukaitis, and S. Kanapeckaite, "Concept of Nernst-type diffusion layer in linear potential sweep voltammetry," Chemija, vol. 2, pp. 138-142, 1998.

[14] J. N. Butler, Ionic Equilibrium (A Mathematical Approach), Addison-Wesley, Reading, Mass, USA, 1964.

[15] C. W. Davies, Ion Association, Butterworths, London UK, 1962. 


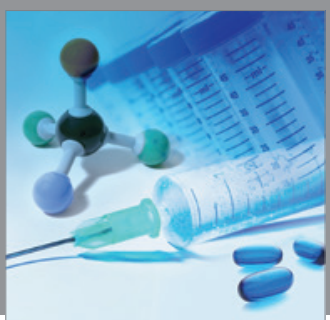

International Journal of

Medicinal Chemistry

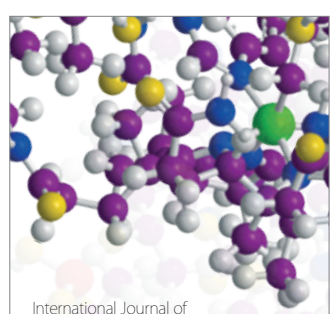

Carbohydrate Chemistry

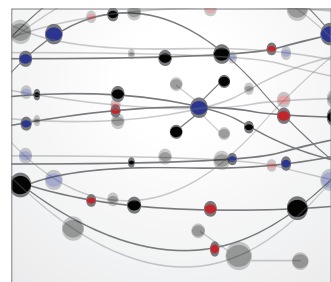

The Scientific World Journal
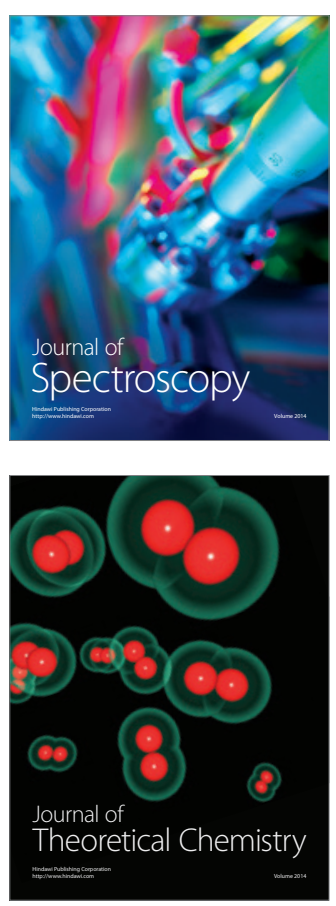
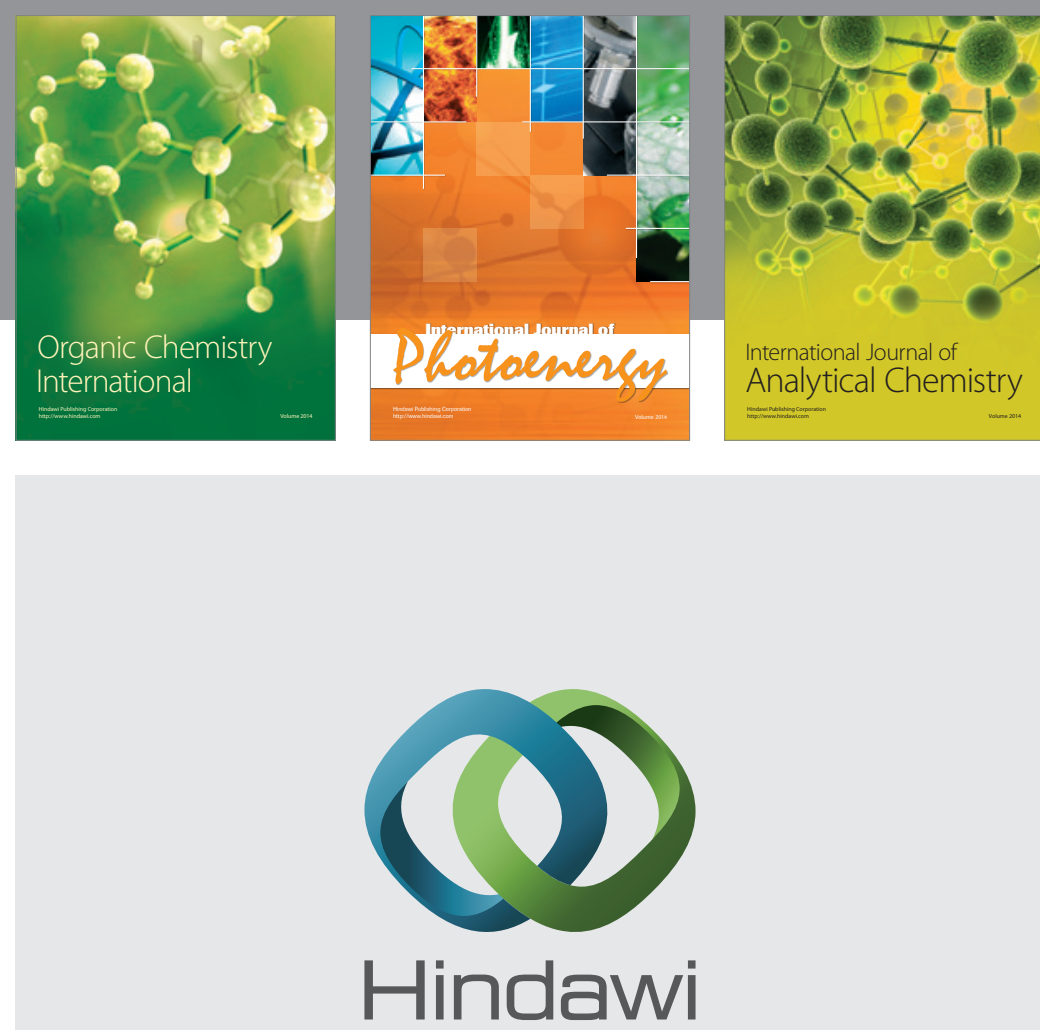

Submit your manuscripts at

http://www.hindawi.com
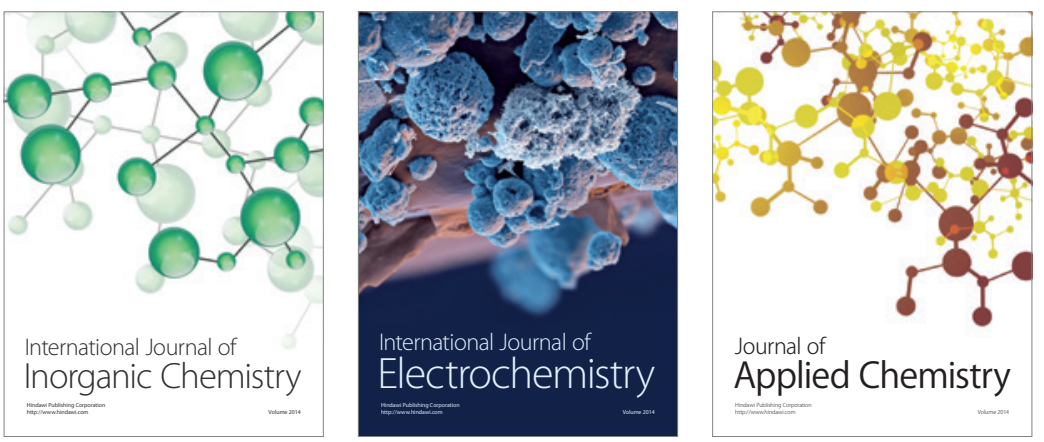

Journal of

Applied Chemistry
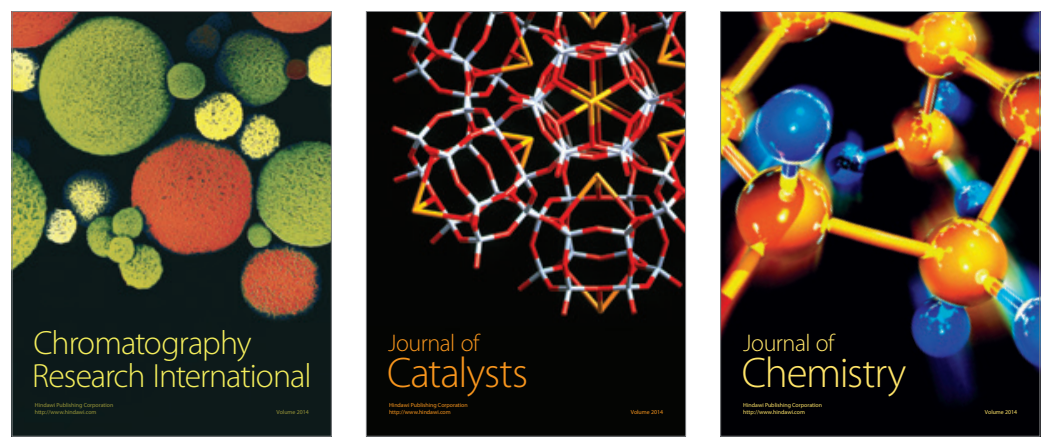
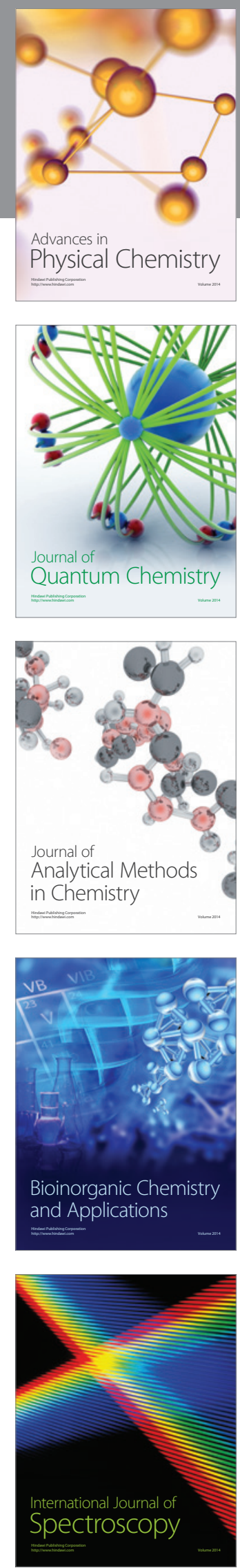